\title{
Bone Densitometry in a Cohort of Egyptian Children with Steroid Sensitive Nephrotic Syndrome.
}

\author{
Samuel H. Makar ${ }^{1}$, Engi A. Ali ${ }^{2}$, Mohamed El Kenany ${ }^{3}$ \& Doaa M. Salah ${ }^{1}$. \\ 1- Department of Pediatrics, Pediatric Nephrology Unit, Faculty of Medicine, Cairo University, Egypt. \\ 2 - Department of Radiology, Faculty of Medicine, Cairo University, Egypt. \\ 3 - Ministry of Health, Cairo, Egypt.
}

\begin{abstract}
\section{Introduction}

Nephrotic syndrome is one of the most frequent glomerular diseases among children. Steroid therapy is still the standard treatment of this disease.
\end{abstract}

\section{Aim of the Study}

This study aims to assess bone density in children with steroid sensitive nephrotic syndrome (SSNS) and to correlate the degree of bone density affection to steroid dose and duration.

\section{Methods}

Fifty children with SSNS 25 steroid dependent/ frequent relapsing (SDNS/FRNS) and 25 infrequently relapsing (IFRNS) patients] were assessed clinically and laboratory. Bone mineral density (BMD) was measured to all included patients by Duel energy X-ray absorptiometry.

\section{Results}

BMD abnormality is significantly increased in SDNS/FRNS group than IFRNS group $(\mathrm{p}=0.0001)$. BMD Z score negatively correlated with relapse frequency-/year $[p=0.001$ and correlation coefficient $(C C)=-0.586$ ]. Bone ache was the only significant complaint in patients with abnormal BMD $(\mathrm{p}=0.004)$. Significant negative correlation was found between BMD $\mathrm{Z}$ score and each of serum alkaline phosphatase (ALP) level and Levamisol therapy duration $\quad(\mathrm{p}<0.05 \& \mathrm{CC}=-0.549$, -0.576 respectively). The best cut off point between patients with normal BMD and abnormal BMD regarding cumulative steroid dose was found to be $>8329.4 \mathrm{mg} / \mathrm{m}^{2}$ with sensitivity of $85 \%$ and specificity of $96.67 \%$ and area under curve (AUC) of 0.92 .

\section{Conclusion}

Impaired BMD in SSNS children significantly correlates with frequency of relapses, serum alkaline phosphatase level, Levamisol therapy duration, steroid doses and duration. At a cumulative steroid dose $>8329.4 \mathrm{mg} / \mathrm{m}^{2}$, BMD impairment is predicted with sensitivity $85 \%$ and specificity $97 \%$.

\section{Keywords}

BMD, Steroids, Nephrotic Syndrome, Relapses

\section{Running title}

Bone Mineral Density in Nephrotic Syndrome.

\section{Corresponding Author Doaa Mohamed Salah, MD.}

Pediatrics Department, Pediatric Nephrology Unit, Cairo University, Cairo, Egypt.

Cairo University Children's Hospital, Mounira Pediatric Hospital (Abou El Reesh), kasr Alainy, Cairo, Egypt.

PO Box: $11562 \quad$ Tel: +201003536578

E-mail: doaasalah@kasralainy.edu.eg, doaamsalah2010@yahoo.com

ORCID: http://orcid.org/0000-0003-2601-9773

\author{
geget: The Journal of the Egyptian Society of Pediatric Nephrology and Transplantation (ESPNT) \\ geget https://geget.journals.ekb.eg/ \\ Published by ESPNT http://espnt.net/ \\ Cohosted by Egyptian Knowledge Bank https://www.ekb.eg
}




\section{Introduction}

Childhood nephrotic syndrome (NS) is a disease of heavy range proteinuria, generalized edema, hypoalbuminemia and hyperlipidemia that typically follows a relapsing/remitting course and often requiring recurrent courses of glucocorticoids (GCs) [1]. Based on the response to $\mathrm{GC}$; this disease is categorized as steroid sensitive (SSNS) with infrequent relapses (IFRNS), steroid-dependent (SDNS) and/or frequently relapsing (FRNS), and steroid-resistant (SRNS) [2].

Children with NS may be at risk for metabolic bone disease because of biochemical derangement caused by renal disease as well as GC therapy [3]. GCs have a suppressive effect on osteoblastogenesis and promote the apoptosis of osteoblasts and osteocytes, thus leading to decreased bone formation [1]. In addition, GCs impair intestinal calcium uptake and increase renal calcium excretion, this negative calcium balance can itself lead to increased bone remodeling and osteoclastic activity due to secondary hyperparathyroidism [4]. The divergent effects of GC therapy on skeletal compartments have implications for dual-energy X-ray absorptiometry (DXA)-based observations about bone mineral density (BMD) development. Given the high cortical density and low trabecular Z-scores observed at diagnosis and after 12 months of GC therapy, growing skeleton may be especially susceptible to these effects [5]. Till now the extent of GC effect on bone loss is poorly quantified. Even alternate-day steroid therapy regimen does not seem to be protective of bone. So we hypothesized that proper assessment of GC effect on bone could be done using cumulative steroid dose rather its regimen of administration.

\section{The aim of the study}

This study aimed to assess BMD in children with SSNS by using DXA, to identify the potentially modifiable contributing factors of BMD impairment and to correlate the degree of bone density affection with steroid dose and duration.

\section{Methods}

This is an analytical cross sectional study that included fifty SSNS children (25 patients with IFRNS, and 25 patients with SDNS/ FRNS) recruited from The Pediatric Nephrology Outpatient Clinic, at our University during the period between June, 2017 and June, 2018. Patients were included according to the following criteria: a) age of onset of NS between 1-18 years, b) SSNS for $\geq 6$ months: infrequent relapsers (IFRNS: < 4 relapses /year) or frequent relapsers (FRNS: $\geq 2$ relapses within 6 months of initial relapse or $\geq 4$ relapse after 10 months of remission) and/ or steroid dependent (SDNS: 2 consequent relapse during corticosteroid therapy withdrawal or after 14 days after treatment was completed). Patients with impaired kidney function, renal tubular defect, other causes of impaired BMD (as those with already documented vitamin D deficiency, metabolic disorders such as irregularities in thyroid hormone and medication as anticonvulsants), and patients with SRNS were excluded from the study.

\section{- Clinical-laboratory evaluation}

Data in term of age of onset, duration of illness, number of relapses, doses/ duration of steroid therapy, symptoms suggestive of osteoporosis as back pain, neck pain, recurrent long bone fractures, stooped posture or breathing difficulty. Routine calcium and/or vitamin D supplementation with steroid therapy during course of the disease was reviewed. Heights and weights of patients were measured and appropriateness for age was checked according to The Egyptian growth curves [6]. Kidney function tests (serum BUN and creatinine and serum calcium, phosphorus and alkaline phosphatase levels were assayed.

\section{- Radiological Assessment (BMD assessment by DXA scan)}

BMD at lumbar spinal region (L2-L4) was measured using DXA scan (Lunar Prodigy Advance Bone Densitometry 2006/7. GE Company, New York, America). Data of BMD levels were interpreted based on WHO (2003) definitions: a) Normal: BMD is within +1 or -1 SD of the young adult mean (T- score $>-1$ ). b) Osteopenia (low bone mass): BMD is between -1 and -2.5 SD below the young adult mean ( $\mathrm{T}$ - score $<-1$ and $>-2.5$ ). c) Osteoporosis: $\mathrm{BMD}$ is $-2.5 \mathrm{SD}$ or more from the young adult mean (T-score $<-2.5$ ). The terms osteopenia and osteoporosis were used in children when $\mathrm{Z}$ scores were less than -1.0 and -2.5 , respectively.

It is to be noted that the diagnosis of osteoporosis should not be made on DXA results alone but should take into account other patient factors that could influence BMD as age, gender, ethnicity, and physiologic maturity level [7]. These factors have been previously studied and are included in most current normative datasets provided by the major DXA manufacturers including that used in the current study.

\section{- Statistical analysis}

Data were analyzed using Statistical Package for Social Science (IBM SPSS) version 20. Qualitative data were presented as number and percentages while quantitative data were presented as mean, standard deviations and ranges when their distribution was found parametric. Two group comparisons were done using Chisquare test for qualitative data and/or Fisher exact test when the expected count in any cell was found $<5$. Two independent group comparisons with quantitative data and parametric distribution were done by using independent t-test. Spearman correlation coefficients were used to assess the correlation between two quantitative parameters in the same group. Receiver operating characteristic curve (ROC) was used to assess the diagnostic accuracy of cumulative dose in prediction of abnormal bone mineral density (BMD) patients with area under curve (AUC), sensitivity, specificity, positive predictive value (PPV) and negative predictive value (NPV). The confidence interval was set to $95 \%$ and the margin of error accepted was set to $5 \%$. So, the p-value was considered significant as the following: $p>0.05$ : nonsignificant, $\mathrm{p}<0.05$ : significant and $\mathrm{p}<0.01$ : highly significant. 


\section{Results}

The mean age of included patients was $8.84( \pm 2.97)$ years with male/ female ratio of 1.6/1. Demographic characteristics, clinical and laboratory data of the studied groups are demonstrated in (Table 1). Patients with FRNS/SDNS had significantly younger age of onset of NS, height less than $3^{\text {rd }}$ percentile for age and sex and increased BMI than those with IFRNS ( $\mathrm{p}=0.001,0.001$ and 0.033 respectively). Serum $\mathrm{PO}_{4}$ and ALP levels were significantly higher in FRNS/SDNS than IFRNS patients $(\mathrm{p}=0.0001)$.

The disease status of patients at assessment is demonstrated in (figure 1); In SDNS/FRNS group 4\% were in relapse, $20 \%$ were assessed during induction of remission and $76 \%$ were in remission on various stages of steroid withdrawal schedule. In IFRNS group; $8 \%$ were assessed during induction of remission, $12 \%$ were in remission on various stages of steroid withdrawal schedule and $80 \%$ were in remission off steroid therapy. Renal biopsy was indicated in 10 patients of the whole studied population; eight patients (32\%) of SDNS/FRNS group and two patients $(8 \%)$ of IFRNS group (IFRNS underwent biopsy due to family history of sibling affection of NS). Eight biopsies (80\%) demonstrated minimal change disease (MCNS), and two biopsies (20\%) were focal segmental glomerulosclerosis (FSGS).

Frequency of relapses, steroid therapy duration and cumulative doses are demonstrated in (Table 2). Immunotherapy other than steroids was administrated in SDNS/FRNS group only as following; ten patients (20\%) received cyclophosphamide, two patients received mycofenolate and eleven patients received cyclosporine. Ten patients (40\%) of SDNS/FRNS used levamisol for a duration of $4.4( \pm 2.27)$ month. $96 \%$ and $20 \%$ of SDNS/FRNS and IFRNS groups received oral calcium and oral vitamin D therapy at assessment respectively.

Table 1 Demographic, clinical and laboratory data of the study groups

\begin{tabular}{|c|c|c|c|c|}
\hline & & SDNS/FRNS & IFRNS & p-value \\
\hline Age & Mean \pm SD & $9.06 \pm 3.28$ & $8.61 \pm 2.66$ & 0.598 \\
\hline Gender & Female / Male & $9(36 \%) / 16(64 \%)$ & $10(40 \%) / 15(60 \%)$ & 0.771 \\
\hline Age of diagnosis & Mean \pm SD & $4.36 \pm 2.41$ & $6.95 \pm 2.97$ & 0.001 \\
\hline Weight & Mean \pm SD & $29.92 \pm 13.33$ & $26.84 \pm 8.21$ & 0.330 \\
\hline Weight $<3^{\text {rd }} \mathbf{C}$ & $\mathrm{n}(\%)$ & $1(4 \%)$ & $2(8 \%)$ & 0.535 \\
\hline Height & Mean \pm SD & $122.8 \pm 13.18$ & $124.52 \pm 15.13$ & 0.670 \\
\hline Height $<3^{\text {rd }} \mathbf{C}$ & $\mathrm{n}(\%)$ & $11(32 \%)$ & $2(8 \%)$ & 0.001 \\
\hline BMI & Mean \pm SD & $18.92 \pm 4.54$ & $16.83 \pm 1.43$ & 0.033 \\
\hline Bony pains & $\mathrm{n}(\%)$ & $15(60 \%)$ & $10(40 \%)$ & 0.157 \\
\hline Truncal obesity & $\mathrm{n}(\%)$ & $6(24 \%)$ & $1(4 \%)$ & 0.042 \\
\hline Fractures & $\mathrm{n}(\%)$ & $1(4 \%)$ & $0(0 \%)$ & 0.312 \\
\hline Infections & $\mathrm{n}(\%)$ & $1(4 \%)$ & $0(0 \%)$ & 0.312 \\
\hline Serum creatinine & Mean \pm SD & $0.48 \pm 0.1$ & $0.49 \pm 0.11$ & 0.718 \\
\hline BUN & Mean \pm SD & $10 \pm 1.8$ & $9.92 \pm 2.12$ & 0.886 \\
\hline Calcium & Mean \pm SD & $9.18 \pm 0.85$ & $9.3 \pm 0.57$ & 0.533 \\
\hline Phosphorus & Mean \pm SD & $4.63 \pm 0.67$ & $3.81 \pm 0.63$ & 0.0001 \\
\hline ALP & Mean \pm SD & $210.84 \pm 79.65$ & $92.44 \pm 39.43$ & 0.0001 \\
\hline GFR & Mean \pm SD & $151.04 \pm 44.57$ & $150.82 \pm 50.1$ & 0.987 \\
\hline Renal biopsy & $\mathrm{n}(\%)$ & $8(32 \%)$ & $2(8 \%)$ & 0.034 \\
\hline
\end{tabular}

BMI (body mass index), BUN (blood urea nitrogen), ALP (alkaline phosphatase), GFR (glomerular filtration rate) 
Table 2 Steroid therapy and frequency of relapse of the study groups

\begin{tabular}{|c|c|c|c|c|c|}
\hline & & \multirow{2}{*}{$\begin{array}{c}\text { SDNS/FRNS } \\
n=25\end{array}$} & \multirow{2}{*}{$\begin{array}{c}\text { IFRNS } \\
\mathrm{n}=\mathbf{2 5}\end{array}$} & \multicolumn{2}{|c|}{ Independent t-test } \\
\hline & & & & $\mathbf{t}$ & p-value \\
\hline \multirow{2}{*}{ Steroid Duration (month) } & Mean \pm SD & $54.68 \pm 23.12$ & $11.28 \pm 6.76$ & \multirow{2}{*}{9.007} & \multirow[b]{2}{*}{0.001} \\
\hline & Range & $20-124$ & $6-38$ & & \\
\hline \multirow{5}{*}{ Frequency of relapses / year } & 0 & 0 & 19 & \multirow{5}{*}{12.75} & \multirow{5}{*}{0.001} \\
\hline & 1 & 2 & 6 & & \\
\hline & 2 & 9 & 0 & & \\
\hline & 3 & 10 & 0 & & \\
\hline & 4 & 4 & 0 & & \\
\hline \multirow{2}{*}{ Cumulative dose $\mathrm{mg} / \mathrm{m}^{2}$} & Mean \pm SD & $14072.88 \pm 9323.04$ & $3755.61 \pm 1362.93$ & \multirow{2}{*}{5.475} & \multirow[b]{2}{*}{0.001} \\
\hline & Range & $4043.94-41544.6$ & $1631.8-7215$ & & \\
\hline \multirow{2}{*}{ Cumulative dose $\mathrm{mg} / \mathrm{kg}$} & Mean \pm SD & $16531.9 \pm 24328$ & $3569.9 \pm 1123.3$ & \multirow{2}{*}{9.134} & \multirow[b]{2}{*}{0.001} \\
\hline & Range & $3841-77877.6$ & $1794.9-6073.8$ & & \\
\hline
\end{tabular}

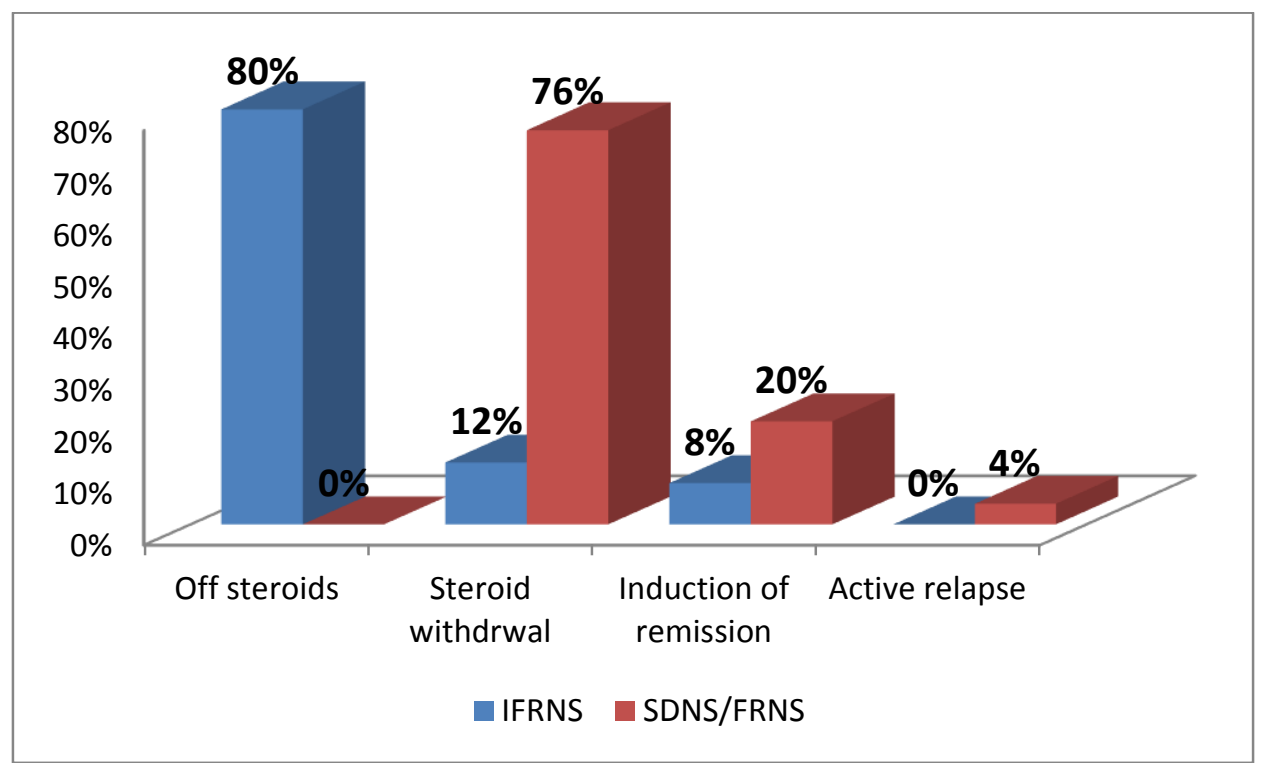

Figure 1 Disease status of the studied groups at assessment

DXA scan of the study groups

BMD was $0.65( \pm 0.13) \mathrm{g} / \mathrm{cm}^{2}$ in SDNS/FRNS group and $0.66( \pm 0.09) \mathrm{g} / \mathrm{cm}^{2}$ in IFRNS group The mean BMD Z-score of SDNS/FRNS group was significantly higher (deviated from normal values) than that of IFRNS group $(p<0.001)$. By interpretation of DXA scan findings; the number of patients with osteopenia/osteoporosis among FRNS/SDNS group was significantly more than that in IFRNS group (Table 3). Included patients were divided into 2 groups based on their DXA scan findings into normal BMD group (30 patients: 22 IFRNS and 8 FRNS/SDNS patients) and abnormal BMD group (20 patients: 3 IFRNS and 17 FRNS/SDNS patients). Both groups were compared as regard different demographic, clinco-laboratory and therapeutic data to extract the significant contributing factors of BMD impairment in children with SSNS. Patients with BMD abnormality have significantly more stunted linear growth (height $<3^{\text {rd }}$ percentile for age and sex), bony aches, elevated serum $\mathrm{PO}_{4}$ and ALP ( $\mathrm{p}=0.001$, $0.004,0.005$ and 0.001 respectively). Steroid duration, steroid cumulative dose and frequency of relapses/year were significantly higher in NS children with abnormal BMD than those with normal BMD (Table 4).

Significant positive correlation was found between BMD Z score and height centile ( $p=0.0001 \& r=0.496)$. Significant negative correlation was found between BMD $\mathrm{Z}$ score and each of age of patients, serum ALP level and Levamisol therapy duration $(\mathrm{p}<0.05$ and $\mathrm{r}=-0.282$, $-0.549,-0.576$ respectively). Frequency of relapses, steroid duration, dependency and cumulative doses significantly negatively correlated with BMD Z score $(\mathrm{p}<0.0001$ and $r=-0.586,-0.528,-0.641,-0.655$ respectively) (Figure 2).

Receiver operating characteristic (ROC) curve showed that the best cut off point between patients with and without normal BMD as regard cumulative steroid dose was > $8329.4 \mathrm{mg} / \mathrm{m}^{2}$ with sensitivity of $85 \%$ and specificity of $96.67 \%$ and area under curve (AUC) of 0.92. In another term, ROC curve showed that the best cut off point between patients with and without normal BMD regarding cumulative dose is $>6073.8 \mathrm{mg} / \mathrm{kg}$ with sensitivity of 
$83.33 \%$ and specificity of $81.25 \%$ and area under curve (AUC) of 0.832 (Figure 3). Unstandardized and standardized linear regression coefficients for correlations between BMD Z-score and steroid cumulative dose, duration and age of diagnosis showed that steroid cumulative dose and duration were significant risk factor for low BMD Z- score and abnormal BMD (Table 5).

Table 3 BMD of the study groups

\begin{tabular}{|c|c|c|c|c|c|}
\hline & & \multirow{2}{*}{$\begin{array}{c}\text { SDNS/FRNS } \\
n=25\end{array}$} & \multirow{2}{*}{$\begin{array}{c}\text { IFRNS } \\
n=25\end{array}$} & \multicolumn{2}{|c|}{ Independent t-test } \\
\hline & & & & $\mathbf{t}$ & p-value \\
\hline \multirow{2}{*}{$\operatorname{BMD}\left(\mathrm{g} / \mathrm{cm}^{2}\right)$} & Mean \pm SD & $0.65 \pm 0.13$ & $0.66 \pm 0.09$ & \multirow{2}{*}{-0.189} & \multirow{2}{*}{0.851} \\
\hline & Range & $0.51-0.99$ & $0.54-0.85$ & & \\
\hline \multirow{2}{*}{ Z score } & Mean \pm SD & $-1.38 \pm 0.82$ & $-0.71 \pm 0.31$ & \multirow{2}{*}{-3.828} & \multirow{2}{*}{$\begin{array}{c}\text { 0.0001 } \\
\text { HS }\end{array}$} \\
\hline & Range & $-3-0$ & $-1.3--0.1$ & & \\
\hline \multirow{5}{*}{ Opinion of BMD } & No osteopenia & $8(32 \%)$ & $22(88 \%)$ & \multirow{5}{*}{$18.533 *$} & \multirow{5}{*}{$\begin{array}{c}\text { 0.001 } \\
\text { HS }\end{array}$} \\
\hline & Mild osteopenia & $6(24 \%)$ & $3(12 \%)$ & & \\
\hline & Moderate osteopenia & $6(24 \%)$ & $0(0 \%)$ & & \\
\hline & Sever osteopenia & $2(8 \%)$ & $0(0 \%)$ & & \\
\hline & Osteoporosis & $3(12 \%)$ & $0(0 \%)$ & & \\
\hline
\end{tabular}

Table 4 Comparison between normal and abnormal BMD patients as regard different variables

\begin{tabular}{|c|c|c|c|c|c|}
\hline & & Normal BMD & Abnormal BMD & \multicolumn{2}{|c|}{ Chi-square test } \\
\hline & & $\mathrm{n}=\mathbf{3 0}$ & $\mathbf{n}=\mathbf{2 0}$ & $X^{2} / t^{*}$ & $\mathbf{p}$ \\
\hline Age (year) & Mean \pm SD & $8.21 \pm 2.55$ & $9.78 \pm 3.35$ & $-1.885^{*}$ & 0.065 \\
\hline Sex & Female/Male & $11(36.7 \%) / 19(63.3)$ & $8(40 \%) / 12(60 \%)$ & 0.057 & 0.812 \\
\hline \multirow{2}{*}{ Diagnosis } & SDNS/FRNS & $8(26.7 \%)$ & $17(85 \%)$ & \multirow{2}{*}{18.365} & \multirow{2}{*}{0.001} \\
\hline & SSNS & $22(73.3 \%)$ & $3(15.0 \%)$ & & \\
\hline Age of diagnosis & Mean \pm SD & $5.97 \pm 2.96$ & $5.17 \pm 3.02$ & $0.932 *$ & 0.356 \\
\hline Height $<3^{\text {rd }}$ percentile & $\mathrm{n}(\%)$ & $11(55 \%)$ & $2(6.7 \%)$ & 14.570 & 0.001 \\
\hline Bony pains & $\mathrm{n}(\%)$ & $10(33.3 \%)$ & $15(75 \%)$ & 8.333 & 0.004 \\
\hline Truncal obesity & $\mathrm{n}(\%)$ & $2(6.7 \%)$ & $5(25 \%)$ & 3.350 & 0.067 \\
\hline Fractures & $\mathrm{n}(\%)$ & $0(0 \%)$ & $1(5 \%)$ & 1.531 & 0.216 \\
\hline Infections & $\mathrm{n}(\%)$ & $0(0 \%)$ & $1(5 \%)$ & 1.531 & 0.216 \\
\hline Calcium & Mean \pm SD & $9.25 \pm 0.69$ & $9.23 \pm 0.77$ & 0.120 & 0.905 \\
\hline Phosphorus & Mean \pm SD & $3.97 \pm 0.72$ & $4.59 \pm 0.70$ & -2.977 & 0.005 \\
\hline ALP & Mean \pm SD & $105.60 \pm 56.47$ & $220.70 \pm 77.23$ & -6.089 & 0.001 \\
\hline \multirow{2}{*}{ Steroid Duration } & Mean \pm SD & $19.53 \pm 16.15$ & $53.15 \pm 29.34$ & \multirow{2}{*}{-5.217} & \multirow{2}{*}{0.001} \\
\hline & Range & $6-60$ & $8-124$ & & \\
\hline \multirow{5}{*}{$\begin{array}{c}\text { Frequency of relapses / } \\
\text { year }\end{array}$} & 0 & $16(53.3 \%)$ & $3(15.0 \%)$ & \multirow{5}{*}{$31.140 *$} & \multirow{5}{*}{0.001} \\
\hline & 1 & $8(26.7 \%)$ & $0(0.0 \%)$ & & \\
\hline & 2 & $6(20.0 \%)$ & $3(15.0 \%)$ & & \\
\hline & 3 & $0(0.0 \%)$ & $11(55.0 \%)$ & & \\
\hline & 4 & $0(0.0 \%)$ & $3(15.0 \%)$ & & \\
\hline \multirow{2}{*}{$\begin{array}{c}\text { Cumulative dose } \\
\mathrm{mg} / \mathrm{m}^{2}\end{array}$} & Mean \pm SD & $4620.60 \pm 2122.92$ & $15354.7 \pm 10125.2$ & \multirow{2}{*}{-5.651} & \multirow[t]{2}{*}{0.001} \\
\hline & Range & $1631.8-9209.3$ & $2952-41544.6$ & & \\
\hline \multirow{2}{*}{$\begin{array}{c}\text { Cumulative dose } \\
\mathrm{mg} / \mathrm{kg}\end{array}$} & Mean \pm SD & $4466.3 \pm 7597.7$ & $18427.7 \pm 55.939 .9$ & \multirow{2}{*}{-9.314} & \multirow[t]{2}{*}{0.001} \\
\hline & Range & $1749.9-13813.9$ & $3510-77877.6$ & & \\
\hline
\end{tabular}


Table 5 Linear regression coefficients for correlations between BMD Z-score and Steroid cumulative dose, duration and age of diagnosis

\begin{tabular}{|c|c|c|c|c|c|}
\hline & \multicolumn{2}{|c|}{ Unstandardized Coefficients } & \multirow{2}{*}{$\begin{array}{c}\text { Standardized Coefficients } \\
\text { Beta }\end{array}$} & \multirow{2}{*}{$\mathbf{t}$} & \multirow{2}{*}{ Sig. } \\
\hline & $\mathbf{B}$ & Std. Error & & & \\
\hline Duration(month) & 0.017 & 0.003 & -0.660 & -6.085 & 0.000 \\
\hline Cumulative dose $\mathrm{mg} / \mathrm{m}^{2}$ & 0.000 & 0.000 & -0.819 & -9.891 & 0.000 \\
\hline Age of diagnosis (year) & 0.014 & 0.034 & 0.06 & 0.418 & 0.678 \\
\hline
\end{tabular}
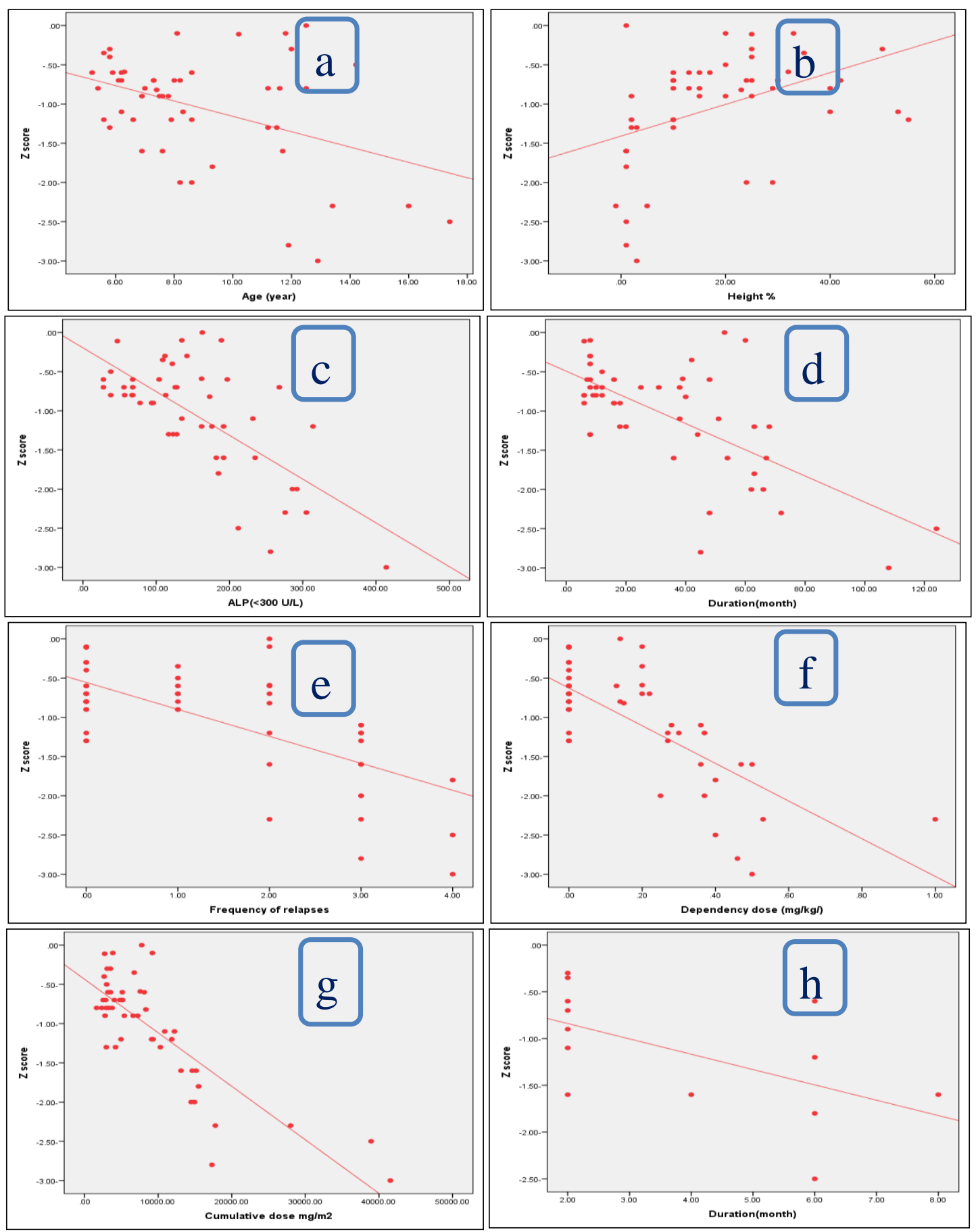

Figure 2 Relation between DEXA $Z$ score and different variables

(a): Relation between DXA- $Z$ score and their age [R $=-0.282^{*}$ and $\left.\mathrm{p}=0.048\right]$.

(b): Relation between DXA- $Z$ score and height for age percentile $[\mathrm{R}=0.496$ and $\mathrm{p}=0.000]$.

(c): Relation between DXA- $Z$ score and serum alkaline phosphatase $[R=-0.549$ and $p=0.000]$.

(d): Relation between DXA- $Z$ score and steroid duration $[R=-0.528$ and $p=0.000]$.

(e): Relation between DXA- $Z$ score and frequency of relapse $[R=-0.586$ and $p=0.000]$.

(f): Relation between DXA- Z score and dependency dose of steroid $[\mathrm{R}=-0.641$ and $\mathrm{p}=0.000]$.

(g): Relation between DXA- $Z$ score and cumulative dose of steroid $[\mathrm{R}=-0.655$ and $\mathrm{p}=0.000]$.

(h): Relation between DXA- Z score and Levamisol duration [R $=-0.576$ and $\mathrm{p}=0.039]$. 

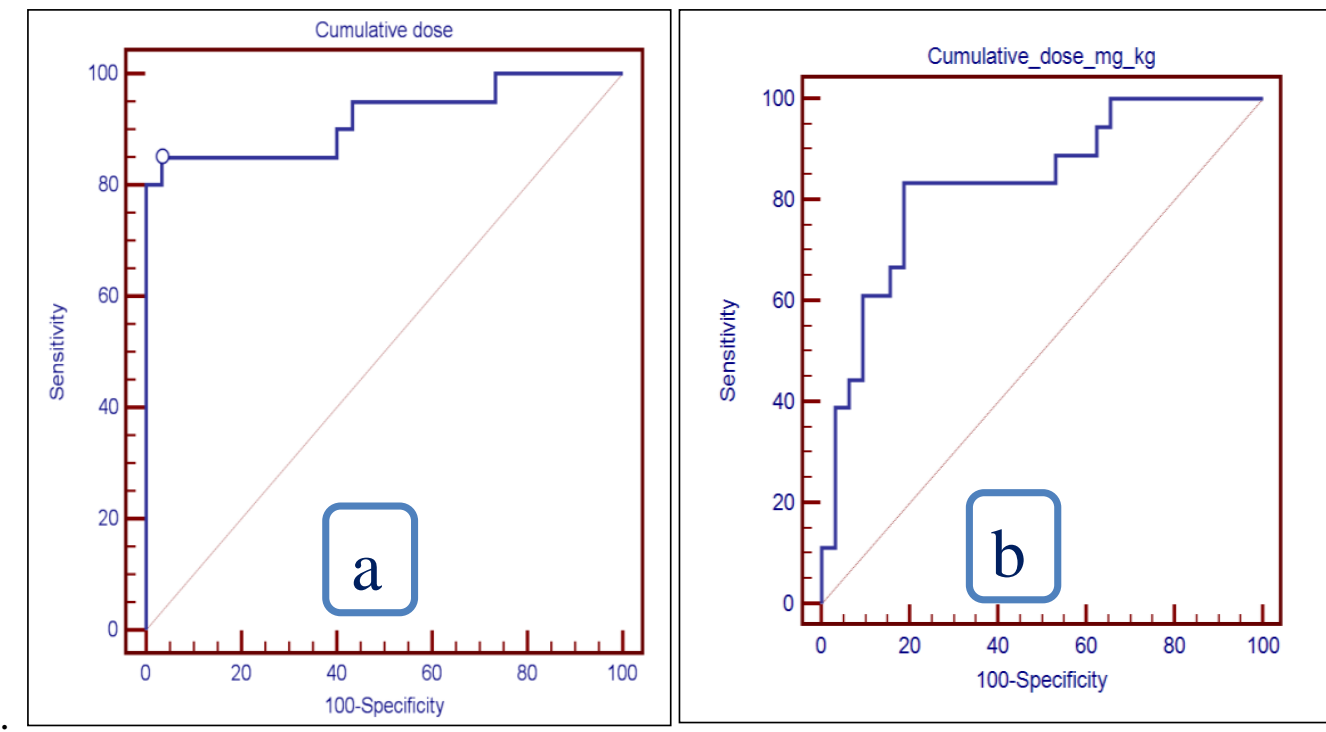

Figure 3 ROC curve for cumulative dose $\mathrm{mg} / \mathrm{kg}$ in prediction of abnormal BMD

(a) ROC curve for cumulative dose $\left(\mathrm{mg} / \mathrm{m}^{2}\right)$ in prediction of abnormal BMD.

(b) ROC curve for cumulative dose $(\mathrm{mg} / \mathrm{kg})$ in prediction of abnormal BMD

\section{Discussion}

Nephrotic syndrome children may suffer from bone metabolism disorders, either due to steroid therapy itself or biochemical changes due to proteinuria that influence bone turnover and mineralization [8].

In this study; we evaluated BMD by using DXA scan for $25 \mathrm{NS}$ children with long term steroid therapy (FRNS/SDNS) as well as for 25 children with IFRNS (19 with first episode NS and 6 patients with single relapse). Most of the studies conducted earlier have enrolled children on long term steroids although Mishra et al., and Bak et al., also included cases with first episode NS along with other group [9, 10]. Yadav et al., however, observed the effect of steroids given for 3 months only for NS children on BMD [11].

It was already published that NS children are shorter in stature, had lower percentage of bone mineral content (BMC) of lumbar and BMD of femoral bones and higher percentage of osteopenia than age and sex matched healthy children [12]. Our analysis clearly revealed that BMD abnormality encountered more in children with FRNS/SDNS than in those with IFRNS. In accordance, Gulati et al studied 100 children (70 children with SDNS/FRNS and 30 children with IFRNS); they concluded that factors predictive of low BMD 'Z-score' were older age at onset, low total calcium intake and greater cumulative steroid dose [13]. Similarly; Basiratnia et al. [12] and more recently El-Mashad et al [1] reported that bone loss can occur in some SDNS patients, especially those with a higher cumulative dose of steroid.

On the other hand, Mishra et al studied 40 children of NS and observed that majority of their patients had normal BMD [9]. Leonard and Zemel also reported no effect on BMC of spine or whole body in children with SSNS and intermittent treatment with high dose prednisolone [14]. They hypothesized that normal BMC and BMD in the patients may be a reflection of the ability of growing skeleton to sustain steroid induced reduction in bone formation and preservation of these parameters in most of their patients [9].

In the present study we did not find significant association between BMD abnormality and serum Ca level $(\mathrm{p}=0.91)$. Hypocalcemia was reported in NS children and was partially explained by GC induced hypocalcemia through decreased $\mathrm{Ca}$ adsorption from the gut and kidneys $[1,15]$. However, some other studies have reported normal serum Ca levels in children with NS due to increased PTH [16].

Our study revealed that SSNS patients with BMD abnormality have significantly elevated serum $\mathrm{PO}_{4}$ and ALP levels than that of their colleagues with normal BMD. Previous reports also documented elevated $\mathrm{PO}_{4}, \mathrm{ALP}$, and PTH in patients with NS vs. controls $[1,16,17]$. It was suggested that hyperparathyroidism in NS children could be attributed to GC induced hypocalcemia $[1,15,18]$. The increased ALP levels during GC therapy in children with NS were also found by Kosan et al. [15] and Mashad et al. [1]. This elevation may be related to increased bone turnover and improvement of massive proteinuria. Incontrary, Banerjee et al. found that serum PTH and ALP levels were significantly lower in the NS patients vs control ( $p=0.01$ and 0.006 respectively) [19]. The significance of the lower median levels of PTH and ALP in the NS is as yet unknown based on data available from their study and may be an effect of small sample size (40 NS cases and 40 controls). Low ALP levels in NS have also been documented in other studies, and one hypothesis is that it is due to an inhibitory action of steroids on osteoblasts [20]. This study reported significant negative correlation between DXA Z score and steroid duration and cumulative dose. This what Ribeiro and his coworkers documented. They reported that growth and spine BMD were both negatively associated with the cumulative dose of GCs and that final height $\mathrm{Z}$-scores were significantly lower in patients receiving $>0.2 \mathrm{mg} / \mathrm{kg} /$ day GC [21].

This study showed a significant negative correlation between DXA Z score and frequency of relapse / year $(p=0.001)$. These results were in accordance with Ribeiro`s 
study. They had their SRNS or SDNS cases presented with more relapses and hence received higher amount of GC, which resulted in a significant loss of height $\mathrm{Z}$-score per year and a total loss of -1 [SD] compared to patients with SSNS receiving a lower dose [21].

The results showed that the best cut off value between NS children with normal BMD and abnormal BMD regarding steroid cumulative dose is $>8329.4 \mathrm{mg} / \mathrm{m}^{2}$ or $>$ $6073.8 \mathrm{mg} / \mathrm{kg}$ with sensitivity of $85 \%-83.33 \%$ and specificity of $96.67 \%-81.25 \%$ and area under curve (AUC) of $92 \%-83.2 \%$ respectively. There was a suggestion about the possible reversibility of GC effects on bone that is over a total intake of $10 \mathrm{~g}$, which could be considered as "the point of no return" in this context, the bone recovery could not be possible, because of substantial and nonreversible disruption of the trabecular network [22].

Our study has limitations in the form of small sample size, lack of concomitant measurement of serum PTH or 25 $\mathrm{OH}$ vitamin $\mathrm{D}$, different disease status of the studied groups and missing the demonstration of the effect of calcium and vitamin D supplementation on BMD. In addition; longitudinal follow up of BMD of included patients is lacking.

\section{Conclusion}

Bone mineral content (BMC) and bone mineral density (BMD) measurements are important parameters of assessment during follow up of NS children that could be a reflection of the ability of the growing skeleton to sustain steroid induced reduction of bone formation. Children with SDNS/FRNS being exposed to long-term steroid therapy are in need of close observation. Age of the child, Levamisol therapy duration and frequency of relapses, steroid cumulative dose and duration are important factors that significantly affect BMD of NS children. Steroid cumulative dose of $\left(8329.4 \mathrm{mg} / \mathrm{m}^{2}-6073.8 . \mathrm{mg} / \mathrm{kg}\right)$ could be considered the cutoff value of BMD abnormality in NS children.

\section{Abbreviations}

\begin{tabular}{|c|c|}
\hline ALP & Alkaline phosphatase \\
\hline AUC & Area under curve \\
\hline BMC & Bone mineral content \\
\hline BMD & Bone mineral density \\
\hline BMI & Body mass index \\
\hline BUN & Blood urea nitrogen \\
\hline $\mathrm{Ca}$ & Calcium \\
\hline DXA & Dual-energy X-ray absorptiometry \\
\hline FSGS & Focal segmental glomerulosclerosis \\
\hline GCs & Glucocorticoids \\
\hline GFR & Glomerular filtration rate \\
\hline IFRNS & Infrequently relapsing nephrotic syndrome \\
\hline MCNS & Minimal change nephrotic syndrome \\
\hline NPV & Negative predictive value \\
\hline NS & Nephrotic syndrome \\
\hline $\mathrm{PO}_{4}$ & Phosphorus \\
\hline PPV & Positive predictive value \\
\hline PTH & Parathyroid hormone \\
\hline ROC & Receiver operating characteristic curve \\
\hline SD & Slandered deviation \\
\hline SDNS & Steroid dependent nephrotic syndrome \\
\hline SRNS & Steroid-resistant nephrotic syndrome \\
\hline SSNS & Steroid sensitive nephrotic syndrome \\
\hline
\end{tabular}

\section{References}

1. El-Mashad G-M, El-Hawya M-A, El-Hefnawy S-M, Mohamed S-M. Bone mineral density in children with idiopathic nephrotic syndrome. J Pediatr (Rio J) 2017; 93(2):142-147.
2. Kidney disease Improving Global Outcomes (KDIGO) 2012. National Kidney Foundation. Kidney International Supplements 2012; 2: 259-274.

3. Mohamed G-B, Abdel-Latif E-A. Serum osteoprotegerin (OPG) in children with primary nephrotic syndrome. Saudi J Kidney Dis Transpl. 2011; 22(5):955-62. 
4. Seibel MJ, Cooper MS, Zhou H. Glucocorticoidinduced osteoporosis: mechanisms, management and future perspectives. Lancet Diabetes Endocrinol 2013; 1: 59-70.

5. Tsampalieros A, Gupta P, Denburg MR, et al., "Glucocorticoid effects on changes in bone mineral density and cortical structure in childhood nephrotic syndrome." Journal of Bone and Mineral Research. 2012; 28.3: 480-488

6. Standard Egyptian Growth. Diabetes Endocrine Metabolism Pediatric Unit Cairo University Children's Hospital.Http://dempuegypt.blogspot.com/. Last revised 29/11/2008. Accessed 10/4/2015.

7. Binkovitz LA, and Henwood MJ. "Pediatric DXA: technique and interpretation." Pediatric radiology 2007; 37(1): 21-31.

8. Feber J, Gaboury I, Ni A, Alos N, et al. Skeletal findings in children recently initiating glucocorticoids for the treatment of nephrotic syndrome. Osteoporos Int 2012; 23:751-760.

9. Mishra OP, Meena SK, Singh SK, et al. Bone mineral density in children with steroid sensitive nephrotic syndrome. Indian J Pediatr. 2009; 76(12):1237-39.

10. Bak M, Serdaroglu E, Guclu R. Prophylactic calcium and vitamin $\mathrm{D}$ treatments in steroid-treated children with nephrotic syndrome. Pediatr Nephrol. 2006; 21(3):350-54.

11. Yadav VK, Sharma S, Debata PK, et al. Change in Bone Mineral Density and Role of Vitamin D and Calcium Supplementation during Treatment of First Episode Nephrotic Syndrome. Journal of Clinical and Diagnostic Research. 2017; 11(9): 18-21.

12. Basiratnia M, Fallahzadeh MH, Derakhshan A et al., Bone mineral density in children with relapsing nephrotic syndrome. Iran J Med Sci 2006; 31 (2): 82-86.

13. Gulati S, Godbole M, Singh U, et al. Are children with idiopathic nephrotic syndrome at risk for metabolic bone disease? Am J Kidney Dis 2003; 41: 1163- 1169.

14. Leonard MB and Zemel BS. Current concepts in pediatric bone disease. Pediatr Clin North Am 2002; 49:143-173.

15. Kosan C, Ayar G, Orbak Z. Effects of steroid treatment on bone mineral metabolism in children with glucocorticoid-sensitive nephrotic syndrome. West Indian Med J. 2012; 61: 627-30.

16. Panczyk-Tomaszewska-M, Adamczuk D, Kisiel A, et al. Markers of bone metabolism in children with nephrotic syndrome treated with corticosteroids. Adv Exp Med Biol.2015; 840:21-8.
17. Esmaeeili M, Azarfar A, Hoseinalizadeh S. Calcium and vitamin $\mathrm{D}$ metabolism in pediatric nephrotic syndrome; an update on the existing literature. Int $\mathbf{J}$ Ped. 2015; 3:103-9.

18. Aceto G, D'Addato O, Messina G, et al. Bone health in children and adolescents with steroidsensitive nephrotic syndrome assessed by DXA and QUS. Pediatr Nephrol. 2014; 29:2147-55

19. Banerjee S, Basu S, Sengupta J. Vitamin D in nephrotic syndrome remission: a case-control study. Pediatr Nephrol. 2013; 28(10):1983-9. 73.

20. Biyikli NK, Emre S, Sirin A, Bilge I. Biochemical bone markers in nephrotic children. Pediatr Nephrol 2004; 19:869-8

21. Ribeiro D, Zawadynski S, Pittet LF, et al., Effect of glucocorticoids on growth and bone mineral density in children with nephrotic syndrome. Eur J Pediatr. 2015; 174 (7):911-7.

22. Carbonare L-D, Arlot M-E, Chavassieux P-M, et al. Comparison of trabecular bone microarchitecture and remodeling in glucocorticoid-induced and postmenopausal osteoporosis. Journal of Bone and Mineral Research 2001; 16.1: 97-103.

\section{Statements}

\section{Ethical approval}

The study protocol was approved by the Ethical Research Committee of Pediatric Department, Faculty of Medicine at Cairo University. All procedures performed in this study were in accordance with the 1964 Helsinki declaration and its later amendments. Informed consent was obtained from guardians of all individual participants included in the study.

\section{Consent for publication \\ "Not applicable"}

\section{Availability of data and material \\ Not applicable"}

\section{Conflict of Interest}

All authors declare that they have no conflict of interest.

\section{Funding Source}

No funding was secured for this study.

\section{Acknowledgment}

Pediatric Nephrology Unit, Pediatric Department, Cairo University Children Hospital, Faculty of Medicine, Cairo University and Radio diagnosis Department, Faculty of Medicine, Cairo University.

$\begin{array}{ll}\text { Submitted } & 21 / 2 / 2020 \\ \text { Revised } & 25 / 3 / 2020 \\ \text { Accepted } & 26 / 3 / 2020 \\ \text { Published online } & 30 / 6 / 2020\end{array}$

